\title{
Gobernar pese a las conciencias. Roger Williams en la frontera entre agustinismo y liberalismo
}

\section{Ruling Despite Consciences. Roger Williams on the Border Between Augustiniamism and Lilberalism}

\author{
Luis Aránguiz Kahn \\ Universidad de Chile, Santiago, Chile \\ Contacto: Irarangu@uc.cl \\ https://orcid.org/0000-0001-7356-6679
}

\section{RESUMEN}

Roger Williams (1604-1683) es considerado uno de los principales autores que fundamentó el camino para ideas constitutivas de la vida política moderna como la libertad de conciencia, la tolerancia y la neutralidad del Estado en materia religiosa. Varias de ellas quedaron plasmadas en su famosa obra El sangriento dogma de la persecución por causa de conciencia (1644). Sin embargo, lo distintivo de Williams no reside únicamente en el hecho de su modernidad, sino en que sostuvo estas ideas recurriendo a la amplitud de la tradición bíblica como de pensamiento cristiano. Por lo anterior, la propuesta de este ensayo consiste en rescatar la dimensión cristiana de Williams y mostrar su continuidad con el pensamiento político de San Agustín en lo que refiere al orden y paz de la ciudad, mediante un análisis comparado de sus ideas. Para ello, se definirán los contornos de la tolerancia religiosa propuesta por Williams en relación con el problema de la libertad de conciencia en El sangriento dogma, a fin de compararlo con algunos rasgos generales del pensamiento agustiniano contenido en La ciudad de Dios. Por último, se mostrará cómo esta noción de tolerancia puede contrastarse con proposiciones de origen liberal, en específico tomando como ejemplo la Carta sobre la tolerancia de John Locke. Esto permitirá ilustrar la distancia que existe entre la posición cristiana y la liberal.

Palabras clave: Roger Williams; Agustín de Hipona; Libertad de Conciencia; Liberalismo; Cristianismo.

\section{ABSTRACT}

Roger Williams (1604-1683) is considered one of the main authors who paved the way for the basic ideas of modern political life, such as freedom of conscience, tolerance, and neutrality of the State in religious matters. Several of them are reflected in his famous work The Bloudy Tenent of Persecution for Cause of Conscience (1644). However, what is distinctive about Williams is not only his modernity, but also that he elaborated these ideas from the breadth of biblical tradition as well as Christian thought. Therefore, this essay seeks to turn to the Christian dimension of Williams and to show how it has continuity with the political thought of Saint Augustine of Hippo regarding order and peace in the city. This will be done through a comparison of both thinkers in key subjects. To do this, I will define the contours of the religious tolerance proposed by Williams in relation to the problem of freedom of conscience in The Bloudy Tenent,comparing this with some general features of Augustinian thought contained in The City of God. Finally, this notion of tolerance will be contrasted with propositions of liberal origin, specifically taking John Locke's Letter on Tolerance as an example. Through this it will be possible to see the differences between a Christian position and a liberal one.

Keywords: Roger Williams; Augustine of Hippo; Freedom of Conscience; Liberalism; Christianity. 


\section{Introducción}

Uno de los temas que ha ganado atención en los últimos años es el de la tolerancia. Pocas cosas importan tanto a las sociedades liberales, que buscan validarse como tales, que el demostrar que en ellas existe una tolerancia ciudadana entre las posiciones diferentes. Sin embargo, puede ocurrir que la tolerancia, de ser un valor, acabe por convertirse en apenas un indicador. Si ella es más que una cifra estadística que muestra cuán abiertos son los ciudadanos a convivir con sus pares que piensan y viven distinto en un sinnúmero de materias, requiere entonces una justificación que explique no solo su existencia, sino el porqué es necesaria. Desde luego, una sociedad liberal retornará a sus fuentes liberales. Pero el origen de la tolerancia liberal de las sociedades liberales no nació en el marco de lo que contemporáneamente se da en llamar multiculturalismo, sino que, como dice John Gray, "nació de las divisiones acaecidas en las sociedades monoculturales" (2000, p. 78) y, específicamente, a partir de los conflictos religiosos que tuvieron lugar en Europa con la Reforma Protestante. En efecto,

[1] a tolerancia liberal presuponía un consenso cultural en materia de valores, aunque permitía diversidad de creencias. Esa tolerancia no constituye una directriz adecuada para la coexistencia pacífica en sociedades en que una profunda diversidad moral ha pasado a ser un hecho establecido de la vida. (Gray, 2000, p. 78)

La diversidad moral que caracteriza a las sociedades contemporáneas permite que distintos modos de vivir convivan, aunque también colisionen según las circunstancias. La tolerancia liberal nació como una forma de permitir la convivencia de creencias religiosas distintas, pero entre las cuales no había posiciones morales sustantivamente diferentes. A esto se refiere Gray al diferenciar estas sociedades monoculturales de las pluriculturales como las contemporáneas. Ahora bien, en su momento la tolerancia se fundamentó de modos múltiples y, no obstante fue la tolerancia en su interpretación liberal la que triunfó, hubo otras formas de justificarla; así, tampoco se trata de un concepto cuya génesis indiscutida sea moderna, porque se la puede encontrar presente ya en la época Medieval (Bejzcy, 1997). Por ello, entendiendo que se trata de una discusión que abarca múltiples perspectivas, en esta ocasión se busca mostrar un caso tempranomoderno que, aunque no trata propiamente sobre la tolerancia, se vincula íntimamente a este problema.

La libertad de conciencia es considerada uno de los valores fundamentales de las sociedades contemporáneas. Aunque esto no es así en todas las latitudes, puede decirse que luego de la Segunda Guerra Mundial se estableció una clara política liberal en el hemisferio occidental que, con más o menos matices, se ha mantenido. Ello también ha pretendido extenderse luego de la caída del muro de Berlín en los países que antes estuvieron tras la cortina de hierro. La Declaración Universal de los Derechos Humanos, en diciembre de 1948, consagraba así este derecho:

Toda persona tiene derecho a la libertad de pensamiento, de conciencia y de religión; este derecho incluye la libertad de cambiar de religión o de creencia, así como la libertad de manifestar su religión o su creencia, individual y colectivamente, tanto en público como en privado, por la enseñanza, la práctica, el culto y la observancia. (Naciones Unidas, 1948, artículo 18)

Como puede notarse en este documento, la noción de "libertad de conciencia" está considerada junto con otras libertades, como la de pensamiento y la de religión. El derecho a estas tres libertades incluye la posibilidad de cambiar de religión o creencia y de manifestarlas en diversas formas. Tanto el hecho de que la libertad de conciencia esté ligada a la libertad de creencia, y el hecho de que esta última implique la posibilidad de cambiar de posición en esa materia, muestra que lo que se designa como "libertad de conciencia" no puede comprenderse sin el marco de las divisiones y partidos religiosos en el siglo XVII, del mismo modo que no puede comprenderse sin atender al problema de la libertad de culto. La discusión por la libertad de conciencia es una discusión tan moderna como religiosa $y$, aunque se la quiera secularizar, hunde inevitablemente sus raíces en la cuestión por la libertad religiosa que tuvo lugar en los países occidentales como consecuencia de la Reforma Protestante del siglo XVI.

Una de las figuras más destacadas en el ámbito de la discusión por la libertad de conciencia - que era, como veremos, también libertad religiosafue el pastor, teólogo y político Roger Williams. 
Contemporáneo de Thomas Hobbes, ministro noconformista en Nueva Inglaterra y fundador de Providence (1636) —un refugio para perseguidos a causa de la religión que luego formaría parte de la naciente colonia de Rhode Island (1644)Williams fue precursor de algunas de las ideas sobre religión y política que luego alcanzarían una notable difusión en la Carta sobre la tolerancia de John Locke, publicada entre 1689 y 1690, que presenta ya un abordaje liberal del problema. Al mismo tiempo, en cuanto cristiano, Williams se hizo cargo de cuestiones fundamentales sobre religión y política que gozaban ya de varios siglos de discusión teológica. Por lo tanto, puede sostenerse que Williams se constituye como un pensador fronterizo entre una concepción cristiana agustiniana y una concepción liberal de la tolerancia religiosa.

\section{Discusión contemporánea}

Actualmente, el pensamiento político de Williams ha sido objeto de discusión en cuanto al lugar que ocupa respecto a la tradición liberal de la tolerancia. Esto puede notarse en la recuperación que Martha Nussbaum hace de él, y la respuesta que recibe por parte de Teresa Bejan. En su libro The New Religious Intolerance, Nussbaum (2012) aborda los límites de lo religioso en las sociedades contemporáneas a propósito, por ejemplo, del crecimiento del islam. Apelando al estoicismo, así como a la tradición liberal en su forma kantiana y rawlsiana, recurre a Williams para situarlo al interior de ese arco conceptual como uno de los promotores de la "acomodación", que sería una defensa más fuerte e incluso "superior" (2012, p. 87) de la libertad religiosa que la provista por la neutralidad lockeana, principalmente debido al hecho de que Williams no se conforma con la tolerancia religiosa, sino que busca la protección de los grupos religiosos minoritarios.

En su Mere Civility, Bejan (2017) respondió a esta interpretación de Williams, observando que al situarlo como precursor de Kant y Rawls del modo en que lo hace Nussbaum, se puede llegar a negar tanto su compromiso religioso como a considerar que su idea de tolerancia implicaba un compromiso más allá del respeto (2017, p. 154), porque, de hecho, no carecía él mismo de un ánimo contendiente en materia religiosa. De este modo, Bejan ha moderado las altas expectativas sobre Williams como un fundador olvidado de la tolerancia moderna, pero al mismo tiempo ha dejado abierta la cuestión respecto a su compromiso religioso. El hecho de que Williams sostuviera sus ideas recurriendo permanentemente a los textos bíblicos y a la historia de la Iglesia es capital para entender la posición desde la cual pensaba.

A la vista de la discusión precedente, la propuesta de este artículo consiste en hacer un ejercicio, reverso si se quiere, que consiste en estudiarlo no en cuanto a su importancia para la tradición liberal, sino con relación al carácter cristiano de su aportación a la tolerancia moderna. Para ello se vuelve necesario reconocer en mayor medida la fundamentación cristiana de sus ideas, especialmente a la luz de la tradición occidental, cuyo referente para nuestros efectos será San Agustín de Hipona. Al obrar así, podrá notarse que la diferencia entre neutralidad/ acomodación de Nussbaum, que muestra a Williams como un defensor más fuerte que Locke, resulta superficial en comparación con las diferencias que se dan entre ambos cuando se trata de definiciones fundamentales. Visto desde el cristianismo, Williams queda más distante de la tradición liberal de lo que Nussbaum quisiera y, por ello, resultará de interés compararlo desde ese punto de vista con Locke.

$\mathrm{Al}$ avanzar en el análisis podrá notarse que, al contrastar la perspectiva cristiana caracterizada por San Agustín y la perspectiva liberal caracterizada por Locke - encontrándose Williams en la frontera entre ambas-, se evidencian tempranamente algunos rasgos del debate que se ha dado en las últimas décadas entre posturas liberales y comunitaristas (Rodríguez, 2010). Esto porque, mientras que en lo que toca a la comprensión del Estado Locke exhibe una postura contractualista e individualista, en el caso de Agustín asistimos a una noción en que el Estado se comprende en función de las comunidades. Como se verá, esta diferencia tiene consecuencias importantes en lo que toca a la comprensión de la tolerancia y la libertad de conciencia. A modo puramente referencial, un ejemplo actual sobre la complejidad de este punto puede encontrarse en el tratamiento que le da Amy Gutman (2004) a los modos de abordar la pluralidad de identidades religiosas en clave grupal e individual en las sociedades democráticas.

Para dar cuenta de la naturaleza fronteriza del pensamiento de Williams, en lo sucesivo se examinará 
en términos generales su noción de la libertad de conciencia y los conceptos sobre los que se sustenta. Luego se revisarán sus semejanzas y diferencias con San Agustín, autor ejemplar del período alto medieval cristiano. Posteriormente se harán contrapuntos entre la noción de libertad de conciencia de Williams con la de tolerancia de John Locke para, finalmente, cerrar con un balance sobre su lugar en la transición del pensamiento cristiano al liberal.

\section{Elementos generales del pensamiento de Williams}

Roger Williams tuvo una vida intensa, por ello no extraña también su intensa actividad intelectual en el ámbito político y religioso ${ }^{1}$. Nacido en Londres en 1603 y formado en Cambridge para ser un dignatario de la Iglesia de Inglaterra o anglicana, Williams se opuso a jurar obediencia al rey para ser ordenado. En cambio, optó por servir como capellán a una familia puritana. Atemorizado por las persecuciones contra su sector, aceptó un puesto pastoral en Nueva Inglaterra. En Boston, al notar que la congregación de la que sería pastor no se había separado de la Iglesia de Inglaterra, comenzó un camino de servicio pastoral en iglesias independientes y manifestó disidencias con la colonia de Massachusetts (por ejemplo, su rechazo a la bandera y escudo) que culminó con su destierro en 1634. La nueva circunstancia obligó a Williams a buscar un lugar donde asentarse. Encontró refugio entre los indios Narrasangetts, lo cual le reportó un aprendizaje cultural que años después le permitió no solo operar como embajador de los ingleses ante los distintos jefes indios, sino también adquirir las tierras en las que fundó Providence en 1636, asentamiento que luego formaría parte de la colonia de Rhode Island. Acompañado de otros disidentes como él, considerados heterodoxos por las iglesias del protestantismo magisterial, Williams construyó Providence sobre principios como la neutralidad religiosa y la libertad de conciencia.

Es en este contexto en el que se comienza a fraguar la obra El sangriento dogma de la persecución por causa de conciencia, publicada en 1644, en medio del retorno que Williams hizo a Inglaterra en 1642. Las animosidades en la Londres de esos días eran de cuidado. El conflicto entre Inglaterra y Escocia, que comprendía la disputa por la implantación de la Iglesia anglicana en una Escocia presbiteriana, tenía también sus propios partidarios y detractores en la ciudad inglesa. En ella pugnaban, en el ámbito parlamentario, un sector que comprendía a realistas y anglicanos, y otro integrado por presbiterianos, congregacionalistas e independientes. Este último sector había convocado en 1643 la creación de la así llamada Asamblea de Westminster, que puso a trabajar a poco más de una centena de teólogos y pastores para resolver disputas de orden teológico para unificar al sector. Por sus ideas, El sangriento dogma puede encuadrarse en este segundo sector y, por tanto, está dirigido a él. Pero también es una forma de contestar a su experiencia en Massachusetts, puesto que en la obra se publica y rebate una carta que el pastor de la Primera Iglesia en Boston, John Cotton, le escribió en contra, personalmente, justificando su destierro. De este modo, Massachusetts queda relacionada con el sector de la oposición a independientes y presbiterianos y aliada con el realismo en la guerra civil.

La obra se articula como un diálogo alegórico entre la Paz y la Verdad. Dado que las opuestas facciones cristianas pugnaban por lo que consideraban verdadero, no es osado sugerir que Williams, al utilizar la fórmula del diálogo entre dos posiciones aparentemente antagónicas, estaba buscando una solución al conflicto entre verdad religiosa y paz social o cívica. ¿Cómo entender la paz? Williams realiza la siguiente distinción:

[...] la Paz de la Ciudad o del Reino es una cosa distinta de la Paz Religiosa o Espiritual, mantenida o profesada por los Ciudadanos. Esta Paz de Culto, dado que en una ciudad puede haber varios, no es más que una Paz falsa. El Pueblo de Dios era y debe ser $\mathcal{N}_{0}$-conformista, no dejándose presionar para alejarse de la verdad, o a practicar un culto falso, y eso sin romper la Paz Civil o de la ciudad propiamente dicha. Y es así como algunas Ciudades florecientes y gloriosas del Mundo mantienen la Paz Civil [...] pues ni en estos lugares ni en otros puede el hombre probar cuál es la verdadera Iglesia de Dios, y consecuentemente, no hay paz espiritual o celestial ${ }^{2}$. (2004, p. 45)

No existe un solo tipo de paz. Existe una paz religiosa o espiritual, y una paz de la ciudad o del reino, la Pax Civitatis, "sea ésta inglesa, escocesa, irlandesa, o más allá, sea una ciudad francesa, española o turca" 
(2004, p. 44). Ahora bien, a la idea según la cual la paz de la ciudad no se puede alcanzar a menos que haya paz espiritual y que esta última, a su vez, solo puede alcanzarse sojuzgando a las demás religiones bajo la verdad de una sola religión, Williams contesta que ambos tipos de paz no son mutuamente excluyentes. $\mathrm{Su}$ propuesta consiste en sostener que se puede disentir en materia de religión sin que esto produzca desorden civil.

Al disociar los tipos de paz, Williams presupone también una disociación entre religión o culto y ciudad o Estado. Una de sus principales preocupaciones era que estos dos ámbitos no se confundiesen; así, todo el trabajo de Williams podría ser resumido como un "asalto sostenido e implacable a la idea del establishment legal de la religión" (Little, 2016, p. 238). En este sentido, señala Williams que:

[...] el Culto que un Estado profesa puede ser contradicho $y$ se puede predicar en su contra sin quiebra alguna de la Paz Civil. Y si se produce tal quiebra, no se debe a tales doctrinas, sino a los violentos y furiosos oponentes de quienes las predican. Quienes piden prisión y espada para los que son contrarios a su opinión o práctica en asuntos de Religión, son las únicas personas que rompen la paz de las Ciudades y Reinos. (2004, p. 62)

En esta afirmación se contiene una respuesta a quienes sostienen que las cuestiones religiosas quiebran la paz civil. Para Williams, aquello no se produce por razones religiosas, sino por la violencia con la que se predican esas ideas. Así, entonces, la religión no supone realmente un problema para la ciudad mientras no se predique violentamente. Más aún, Williams invierte este planteamiento señalando que quienes persiguen con la espada - es decir, el poder coercitivo del Estado - a quienes pacíficamente piensan y predican diferente, ellos son los que rompen la paz de las ciudades.

Aún más, tal importancia tiene disociar religión y violencia que Williams llegó a afirmar, en un contexto de fragorosas disputas por la ortodoxia cristiana, que sería un error pensar que incluso para la paz de la ciudad es necesaria la religión verdadera - cualquiera sea esta- cuando, en sus palabras, "tantos Reinos y Gobiernos del Mundo han disfrutado por tantísimo tiempo de tan larga paz y tranquilidad a pesar de estar su Religión tan corrupta que ni siquiera se conocía el nombre de Fesucristo entre ellos" (2004, p. 174). Una afirmación como esta en un contexto en que distintos partidos cristianos - sin contar otras religiones - pugnaban por la prevalencia de su visión, resultaría a lo menos incomprensible si no se tomara nota del concepto de poder político de nuestro autor. Para Williams,

[...] desde el principio del Mundo Dios armó al Estado Civil con Padres, Señores y Magistrados, para castigar a los hacedores del mal, cuyas acciones son juzgadas por Padres, Señores y Magistrados, que castigan en consecuencia las transgresiones de la paz y bienestar de su Estado Civil, sean Familias, Ciudades y Reinos. (2004, p. 70-71)

Lo que Williams formula como "Estado Civil" no es otra cosa que el poder organizado jerárquicamente en una sociedad determinada para castigar los delitos, es decir, aquello que atenta contra la paz de la ciudad. Y este poder viene "armado" por Dios desde el principio, esto es, desde el momento en que los humanos se organizan como comunidad política. En este punto cabe preguntarse qué es lo que constituye o funda una comunidad de esta naturaleza. Williams ofrece una definición clásica: "Las familias son la base del gobierno, pues, ¿qué es un Estado sino una unión de familias de acuerdo en vivir juntas para el bien común?" (2004, p. 167). La comunidad política, el Estado, es una unión de familias, es decir, el fundamento del Estado es la unión de comunidades familiares. Esto supone que ellas lo hacen posible; y es a partir de ellas, también, que pueden fraguarse otro tipo de organizaciones al interior de una ciudad o Estado.

Disociada la paz espiritual y la paz de la ciudad, y entendida la ciudad como una entidad independiente de la religión, cabe ahora enfrentarse al hecho de que, según Williams, "la Iglesia y el Estado Civil, esto es la Iglesia y el Mundo, se han convertido ambos en el mismo rebaño" (2004, p. 119). ¿Qué es la Iglesia? Un tan extenso como clarificador párrafo puede ayudar:

[...] la Iglesia la compañia de fieles, estén equivocados o acertados, es como el Cuerpo o Colegio de Médicos en una Ciudad, como las Corporaciones, Sociedades o Compañias de las Indias o de los Mercaderes Turcos, o cualquier otra Sociedad o Compañia de Londres. Estas 
compañías pueden mantener sus propios Colegios, Registros, tener sus disputas, y en los asuntos que se refieren a su Sociedad los miembros pueden disentir, dividirse en Cismas y Facciones, demandarse y acusarse mutuamente ante la Ley, y hasta llegar al mismo extremo de irse disolviendo hasta desaparecer, y que la Paz de la Ciudad no se vea en ninguna medida resentida o perturbada, pues la esencia o el ser de la Ciudad, así como su bienestar y paz, es algo esencialmente distinto de la paz particular de esas Sociedades. Los Tribunales de la Ciudad, las Leyes de la Ciudad, los Castigos de la Ciudad, son diferentes de los de estas agrupaciones. La Ciudad estaba antes que ellas, y permanece absoluta y entera cuando esa Corporación o Sociedad se desmorona. (2004, p. 45 ss.)

Una definición como esta podría resultar comprometedora para alguien que se considera noconformista en temas teológicos. ¿Cómo es posible que alguien que busca la verdad cristiana acabe por comparar a la Iglesia, la institución fundada por Cristo, con una corporación o sociedad cualquiera? Esta aparente contradicción se soluciona tomando en consideración que la definición precedente es realizada en el marco de una comprensión corporativa de la sociedad en la cual la Iglesia, es decir, los cristianos en sus diversas formas, son una de las tantas agrupaciones que componen la vida común. En dicho sentido estricto, Williams observa que el estatuto de estas agrupaciones es distinto del de la ciudad, porque sus fines son distintos y, por lo tanto, también sus normas son distintas. Por eso, para Williams es deseable que un Estado no promueva religión alguna, pues la razón por la cual las familias se han agrupado para organizar una comunidad política no es para que sus autoridades tomen posición por una u otra, sino para castigar el delito en aras de la mantención de la paz entre los grupos diversos y así, por tanto, salvaguardar una vida común pacífica. Ahora bien, esto no obsta que "la Iglesia puede ayudar a la prosperidad del Estado a través de sus medios espirituales" (2004, p. 155).

Williams también hará contraste con teorías distintas. Piénsese, por ejemplo, con la Ginebra de Calvino, caracterizada por ser un régimen en el que dominaba una ortodoxia protestante:

Las ordenanzas y la disciplina de Cristo Fesús, aunque aplicadas equivocada y profanamente a hombres naturales y sin regenerar, pueden ofrecer una apariencia de civilidad y moralidad de los mismos, como en Ginebra o en otros lugares, pues la simple luz que arroja la mera sombra de la Doctrina de Cristo refleja la vergüenza del barbarismo y la incivilidad; pero, aun así, afirmo que la incorrecta aplicación de las Ordenanzas a personas sin regenerar y no arrepentidas, conduce a sus almas a un terrible sopor, en el que sueñan su propio estado de santidad, y así se envían millones de almas al infierno en una cierta expectación de la más falsa Salvación. (2004, p. 156)

La preocupación central no está en la aplicación coercitiva de cierto cúmulo de normas cristianas, sino sobre todo en el hecho de que aquello se aplique fuera de los límites de la Iglesia entendida como comunidad de quienes aceptan vivir bajo ciertas normas. El problema, por tanto, es la aplicación de normas fuera de su esfera de dominio, a personas que por conciencia propia no quieren sujetarse a ellas. El efecto que ellas tienen sobre quienes no las siguen de buena conciencia es, finalmente, superficial. Porque el Estado no tiene la capacidad para gobernar la conciencia y solo puede imponer un comportamiento externo. La paz de la ciudad es distinta de la paz espiritual porque mientras que esta última obedece a convicciones de conciencia, la primera solamente obedece a la restricción de los delitos que afectan a la comunidad. De aquí que cobre sentido la distinción hecha por David Little según la cual lo que Williams teme "es la condición de una religión establecida en la que ambos, Iglesia y Estado, son mutuamente degradados y corrompidos por errar en observar la distinción crítica entre el foro interior y el exterior" (2016, p. $241^{3}$ ). Williams no era antiteocrático (Little, 2016, p. 258) solo porque temiera que el Estado se entrometiera en la vida de la Iglesia - como buen no-conformista-, sino también porque temía que la Iglesia se entrometiera en las competencias que son propias del Estado. Esta mutua corrupción es la que en suma hace confusa la distinción entre el foro externo y el interno de un ciudadano o de una comunidad religiosa.

$$
\text { Un segundo contrapunto con otro }
$$
pensamiento cristiano podría ser el que hizo Williams con Agustín de Hipona respecto al problema de la persecución. En efecto, aunque sin nombrar fuente, recoge Williams una afirmación en la que Agustín sostiene la necesidad de castigar en 
el cuerpo a quienes "matan almas". Luego de una refutación bíblica sobre esta práctica Williams, como respondiéndole a Agustín, señala:

[...] por último, deja que un hombre sea un Falso Maestro, un Hereje, el mismo Balaán, una Bruja espiritual, un Lobo, un Perseguidor, que exhale blasfemias contra Cristo, y que cometa los más terribles asesinatos de sus seguidores, así fue Pablo (Hch. 9). Y yo digo que estos que parecen asesinos de almas hoy, por la gracia de Cristo, serán salvadores de almas mañana. (2004, p. 143)

Esta alusión al de Hipona no es casual si se considera que en el medievo se recurría a él no para justificar la tolerancia, sino más bien la compulsión hacia los cismáticos y los no-cristianos, y que más cercano a su experiencia, en el sector de la reforma magisterial, se "adhirió mayormente a la posición de Agustín sobre la tolerancia dentro de la Iglesia y a la intolerancia hacia los disidentes externos" (Mansuy y Svensson, 2013, p. 1816 ss) de las iglesias establecidas, tales como los anabautistas. Pese a que en esta materia Williams exhibe una diferencia importante con Agustín, presumiblemente debido en parte al uso que se le daba por esos días, el hecho es que, en otros temas, fue un heredero del pensamiento agustiniano.

\section{Williams, heredero fronterizo de Agustín}

Como vimos, Roger Williams disentía con Agustín de Hipona (354-430) en lo que toca a persecución por causa de conciencia, lo que en este contexto equivale a decir, persecución por causa de creencia. Pero cpor qué pensaba Agustín de esta manera? Y, por otra parte ¿en qué puntos fue Williams un heredero de Agustín?

La aprobación que Agustín daba a la persecución por causa de creencia vino dada por un contexto particular. En la parte africana del Imperio romano había cobrado fuerza la doctrina donatista ${ }^{4}$. Algunos de sus promotores estaban adoptando tácticas violentas y es presuntamente por ello que Agustín habría adoptado una posición a favor de la persecución en ese caso. De acuerdo con John Rist, "tal parece que, aunque en ese tiempo la persecución de los donatistas fue adoptada primeramente en defensa personal, sin embargo, pronto se hizo claramente efectivo para asegurar conversiones" (2016, p. 112). Con todo, el mismo Rist señala que "la práctica de castigar a los obispos heréticos y sus seguidores o inspiradores con el exilio y la privación de sus sedes, o incluso de sus vidas (al menos indirectamente), estaba bien establecida bastante antes de que Agustín fuera ordenado obispo" (2016, p. 111).

Aun cuando la práctica de la persecución venía con anterioridad a Agustín, e incluso cuando su aprobación de la persecución obedecía a razones contextuales, el filósofo de Hipona estaba convencido de la pertinencia de que el Imperio facilitara la expansión del cristianismo. De aquí que su emperador favorito fuera Teodosio, quien fue activo en la supresión del paganismo (Rist, 2016, p. 109). Agustín consideraba que "el imperio cristiano no era el único instrumento de Dios y que no era un instrumento perfecto, pero que el imperio era útil" (Kaufman, 1990, p. 146), y contaba con que un gobierno que mantuviera la paz era necesario para que siguiera expandiéndose el cristianismo (Kaufman, 1990, p. 147). Con todo, el hecho de que su aceptación de la persecución al donatismo haya respondido a un contexto preciso permite suponer que, si bien su posición teológica de rechazo a esa corriente era un elemento necesario para el consentimiento de coerción, la razón suficiente no era aquella, sino la violencia de sectores donatistas contra el imperio.

Ahora bien, pese a esta diferencia, Williams es heredero de San Agustín en al menos cuatro ideas que son claramente formuladas en su obra La ciudad de Dios, escrita entre los años 412 y 426 . En primer lugar, esta obra arranca desde la noción alegórica según la cual existen dos ciudades: la terrena y la celestial. La terrena es originada por "el amor de sí mismo hasta el desprecio de Dios", y la segunda por "el amor de Dios hasta el desprecio de sí" (Agustín, 2009, p. 582). La ciudad terrena es, así, figura del mundo ordenado de acuerdo con nociones no-cristianas; y la ciudad de Dios es la Iglesia de Cristo, cuya existencia si bien tiene lugar en la tierra, se ordena a la obediencia a Dios.

En segundo lugar, y aparejado al punto anterior, en Agustín encontramos la distinción entre dos tipos de paz: una de la ciudad terrenal y una de la ciudad celeste. En sus palabras,

[...] la paz de una ciudad es la concordia[...] la paz de una ciudad es la concordia bien ordenada en el gobierno y en la obediencia 
de sus ciudadanos. La paz de la ciudad celeste es la sociedad perfectamente ordenada y perfectamente armoniosa en el gozar de Dios y en el mutuo gozo en Dios. (2009, p. 849)

La paz terrena es la mantención del acuerdo entre los distintos elementos que componen la ciudad; la paz celeste, a diferencia de la anterior, es perfecta y orientada hacia Dios. Para alcanzar el equilibrio de las voluntades humanas, la ciudad terrena requiere de "la armonía bien ordenada del mando y la obediencia de sus ciudadanos" (Agustín, 2009, p. 857). Ahora bien, esto no significa que Agustín conciba el mundo de manera dualista. La paz de la ciudad celeste es, por su fin, superior en principio a la paz de la ciudad terrena. A su vez, dependen del orden cósmico regido "por una auténtica ley eterna, que respalda el mismo Dios" como señala Saturnino Álvarez (1960, p. 51).

En tercer lugar, Agustín concede a la familia un lugar fundamental en el orden terreno. En efecto, "la familia debe ser el principio y la parte mínima de la ciudad" (2009, p. 856). En cuanto principio y parte mínima, la familia se ordena a un fin. En ella se cultiva la convivencia entre obediencia y mando, de modo que la paz doméstica se vuelve un elemento de importancia para la paz de la ciudad. Así como los ciudadanos han de buscar una convivencia armoniosa en este orden, asimismo ha de hacer la familia. El padre de familia, enseña Agustín, ha de tomar los preceptos de la ciudad para que su casa sea así ordenada a la paz del modo que es ordenada la paz en la ciudad. En el caso de Williams, la familia también es el fundamento de la vida de la ciudad o Estado, constituyéndose de hecho la unidad política a partir de la unión de familias. En ambos casos estamos ante la clara noción de que la unidad política es forjada no en función de individuos atomizados, sino de comunidades humanas y las del tipo más natural u orgánico imaginable.

Por último, en Agustín también encontramos una concepción de la Iglesia, o la ciudad de Dios, que halla eco en el pensamiento de Williams. Dado que ambas ciudades son distintas, Agustín considera que también han de ser distintas sus reglas:

Dado que la ciudad celestial sólo reconoce a un Dios como digno de adoración y de rendirle culto $[\ldots]$, y cree con religiosa fidelidad que es exclusivo de Dios, el hecho es que no puede tener comunes las leyes religiosas con la ciudad terrena. (2009, p. 858)

En otros términos, dos ciudades distintas tienen distintas normas ante todo porque tienen distintos fines. Muchas ciudades son las de los hombres, pero todas ellas tienen el mismo fin. La ciudad de Dios es una sola y, así, tiene un fin distinto a todas las otras ciudades. Pese a esto, la concepción agustiniana también admite, como Williams años después, que la ciudad celestial puede contribuir a la estabilidad de la ciudad terrena:

[...] en esta su vida como extranjera, la ciudad celestial se sirve también de la paz terrena y protege, e incluso desea - hasta donde lo permitan la piedad y la religión-el entendimiento de las voluntades humanas en el campo de las realidades transitorias de esta vida. (2009, p. 858)

Así pues, ya en Agustín, poco más de 1000 años antes de Roger Williams, encontramos una clara distinción entre la Iglesia y la ciudad, la diferenciación entre la paz de ambas ciudades, una noción de la ciudad terrena fundamentada en la familia como unidad mínima y una noción de la diferenciación de órdenes normativos de ambas ciudades. Si bien en todo ello se observa una continuidad entre uno y otro, tampoco Williams adhirió completamente a la perspectiva agustiniana, disintiendo nada menos que en la materia central de su libro, la persecución por causa de conciencia y, en específico, por diferencias religiosas. Ahora bien, esta diferencia de ningún modo opaca el hecho de que Williams entendía que podía haber diferencias irreconciliables entre grupos religiosos. Lo que le preocupaba era que esas diferencias no llevasen a persecuciones y coacción de conciencia. En otros términos, a Williams no le importaba que no hubiese acuerdo, sino que no hubiese libertad para el desacuerdo. Tal vez por ello es que, como veremos pronto, no apelaba a un concepto transversal como la tolerancia, capaz de orientar una mejor disposición en medio de las diferencias, del modo que lo haría Locke en acuerdo con una mentalidad liberal forjada en una sociedad monocultural cristiana. 


\section{Williams, precursor de frontera de la tolerancia liberal}

Williams no solo extrae ideas del pasado y, a la vez, toma distancia de ellas. Se encuentra en un período de discusiones que serán definitorias para la fundamentación de un nuevo tipo de orden, del cual él ya era apenas un último aliento. Una de las razones por las cuales es conocido el filósofo inglés John Locke (1632-1704), además de su restante contribución al pensamiento liberal, es por el tratamiento que le dio al tema de la tolerancia. A este respecto, cabe señalar especialmente su Carta sobre la tolerancia, publicada en los Países Bajos en 1689. En este documento, como su nombre lo indica, puede apreciarse una clara defensa de la tolerancia y la neutralidad del Estado en materia religiosa. Aun cuando la tolerancia no fue su opción en un principio, sus posiciones fueron cambiando con los años, de tal modo que acabó defendiendo lo mismo que Roger Williams unos cincuenta años después (Bejan, 2017, p. 115) y "como Williams y Hobbes antes que él, temía que las odiosidades privadas y la condenación mutua por desacuerdos fundamentales podría disolver el vinculum societatis" (Bejan, 2017, p. 114).

Es por lo anterior que Locke hará una distinción entre la incivilidad y la confianza. Como señala Teresa Bejan:

Aislar la incivilidad como el catalizador para el ciclo devastador de los odios religiosos, hizo posible a Locke contradecir las demandas de sus antiguos aliados. La confianza, y no la uniformidad, era el verdadero vínculo de la sociedad [Bond of Society]; por lo tanto, la tolerancia sería posible en la medida en que la confianza mutua fuera preservada. (2017, p. 122)

Así las cosas, en Locke se encuentra una operación similar a la de Williams, en cuanto que se localiza el peligro para la paz civil no en las diferencias religiosas, sino en las acciones violentas que se realizan en nombre de dichas diferencias. La solución ofrecida por Locke es una de orden "civilitario" ["civiliatarian"]: el problema no era el desacuerdo en sí mismo, sino el modo en que se realizaba (Bejan, 2017, p. 133). Ello nos permite ya considerar algunas cuestiones relativas a su concepto de la tolerancia en relación con el Estado.
En lo que toca al Estado, vemos que Locke mantiene con Williams una distinción clara entre el orden de las Iglesias y el de la ciudad o Estado. Refiriéndose a la importancia de separar ambos dominios normativos, Locke afirmó que:

Si, por lo tanto, tal poder fuera conferido al magistrado civil en cuestiones espirituales (como en Ginebra, por ejemplo), podría extirpar, por la violencia y la sangre, la religión que allí es reputada idólatra, en virtud de la misma regla por la cual otro magistrado, en algún país vecino, puede oprimir la religión reformada o, en la India, la cristiana. (2018, p. 41)

Como puede notarse, está presente aquí la neutralidad del Estado en materia religiosa y, también, en línea con Williams, una mención poco auspiciosa al caso de la Ginebra de Calvino, como un modelo opuesto al de la tolerancia que impulsaban tanto Williams como Locke. De hecho, las únicas organizaciones que según Locke (2018) no pueden tolerarse son aquellas que pudiesen tener ideas que vayan contra el orden civil (p. 54), aquellos sujetos que busquen de algún modo oponerse a los derechos civiles de los demás (p. 55), aquella Iglesia cuya pertenencia implique lealtad a otro príncipe (p. 56) y, por último, quienes nieguen la existencia de Dios (p. 57). De todas estas razones de intolerancia, Roger Williams habría concordado con las dos primeras. Excluidas estas cuatro excepciones, Locke señaló que "el papel de las leyes no es cuidar de la verdad de las opiniones, sino de la seguridad del Estado y de los bienes y de la persona de cada hombre en particular" (2018, p. 48). Así, la tarea de las leyes no es tratar diferencias religiosas, sino cuidar del orden de la ciudad. No obstante, en esta afirmación puede observarse una diferencia de fundamento con Williams. Locke hace un énfasis en el cuidado de "cada hombre en particular", imprimiendo así un enfoque liberal. La razón de este énfasis puede encontrarse en la comprensión que Locke tiene del origen del Estado. La diferencia con Williams reside en que mientras que, para él, la ciudad o comunidad política se constituye a partir de la unión de varias familias, siendo esta el fundamento de la vida común en línea con San Agustín, para Locke en cambio el Estado es "una sociedad de hombres constituida solamente para procurar, preservar y hacer avanzar sus propios intereses de índole civil” (2018, p. 8). En 
esta diferencia es posible notar claramente el lugar fronterizo que le cabe a Williams entre el cristianismo medieval y una versión liberal del mismo.

Otra diferencia con Williams, en línea con la precedente, es que Locke cifra su esperanza de civilidad específicamente en los individuos en cuanto que es al individuo, y no solo a una comunidad determinada, al que se le hace una demanda ética de tolerancia mutua (Bejan, 2017, p. 130). La tolerancia no se entiende en Locke únicamente como la adopción de una neutralidad estatal en materia religiosa, como ocurriría en el caso de Williams. Esta posición, que podríamos considerar negativa, señala que el Estado simplemente debe abstenerse de los asuntos religiosos y regular únicamente aquello que tiene que ver con la violencia que provoca inestabilidad civil. Si bien Locke ciertamente la comparte, añade a su vez un componente positivo. Este componente es depositar confianza en la capacidad de los individuos para tolerar la diferencia civilizadamente. En la mirada de Bejan, es por ello que en su Carta puso una atención considerable a la tolerancia como una práctica interpersonal de las personas, lidiando con la diferencia en su vida cotidiana (2017, p. 130). Este elemento positivo en cuanto a tolerancia tiene un argumento cristiano que toca en lo esencial la comprensión que Locke tenía del cristianismo.

Mientras que en Williams la Iglesia es entendida figuradamente como una corporación que convive con otras corporaciones al interior de la ciudad, Locke nuevamente deja a la vista su mirada liberal al definir a la Iglesia como "una sociedad voluntaria de hombres, unidos por acuerdo mutuo con el objeto de rendir culto públicamente a Dios de la manera que ellos juzgan aceptable a Él y eficaz para la salvación de sus almas" (2018, p. 13). Una definición contractual liberal como esta, que explica el origen de la comunidad eclesiástica en el individuo, es impensable en un San Agustín y para el medievo en general. Tal vez podría pensarse que tiene cierta sintonía con el pensamiento de Roger Williams en la medida en que él comparó a las agrupaciones religiosas con otras corporaciones, como por ejemplo un colegio de médicos o una compañía de indias. Sin embargo, la diferencia fundamental reside en el hecho de que Williams comparó a las iglesias con otras corporaciones no porque pensara que eran esencialmente equivalentes, sino solo porque eran equivalentes en cuanto a su lugar en el orden de la ciudad.

El cambio operado por Locke rebasa largamente esta idea de Williams en la medida en que redefine la naturaleza de las organizaciones religiosas, y en especial las Iglesias, desde un punto de vista liberal en el que es el acuerdo mutuo y racional entre individuos el que permite su conformación, noción que atenta al corazón mismo de lo que un cristiano antiguo y medieval habría entendido por Iglesia. La presencia de este giro, lejos de ser apenas un posible sesgo filosófico, es determinante para comprender el concepto que Locke pretende sostener.

De todas formas, Locke se mantiene cerca de Williams en cuanto a su noción de la diferencia de ordenes normativos:

[...] el fin de una sociedad religiosa es el culto público de Dios y, a través de él, la adquisición de la vida eterna. Toda disciplina debe, por tanto, tender a este fin y todas las leyes eclesiásticas deben limitarse a él. (2018, p. 16)

En otros términos, parte de la tolerancia implica que las normas de la Iglesia se apliquen solamente a aquellos que voluntariamente se someten a una organización religiosa y, por tanto, no a aquellos que se encuentran fuera de los límites de la organización.

Con una definición liberal contractualista de la Iglesia y una definición liberal individualista de los fundamentos del orden del Estado, se hace posible comprender por qué Locke sitúa a la tolerancia más allá de la neutralidad del Estado. Habida cuenta de ello, cuando afirma que "la tolerancia es la característica principal de la verdadera Iglesia" (2018, p. 3), lo que está señalando no es que las comunidades religiosas debieran dejar de perseguirse unas a otras y discutir civilizadamente sus diferencias, como era lo que pretendía Williams, sino que los individuos que pertenecen a ellas han de practicar la tolerancia. En otros términos, Locke traslada el conflicto teológico desde las agrupaciones hacia los individuos y, al cifrar la tolerancia en el individuo, que es quien conforma la Iglesia, y no en la comunidad eclesiástica en cuanto tal, la paz cívica deja de entenderse como una armonía 
entre grupos diversos y pasa a ser una armonía entre individuos diversos. Al restar importancia a las comunidades y otorgarla a los individuos, esta operación deja a la vista que la paz social, junto con Williams, se logra con una acción negativa del Estado -adoptar una posición neutral en temas religiosos - ; pero, al mismo tiempo, contra Williams, cifra la esperanza de la paz social en la voluntad individual del creyente y no en la inexistente voluntad de los grupos religiosos por resolver sus diferencias corporativamente. La tolerancia ya no depende del abandono de la violencia y la coerción entre grupos opuestos, sino de una disposición, también, de conciencia individual.

Atendido todo lo anterior, es posible ahora ver por qué, si bien tratan un tema similar y concuerdan en algunos aspectos, Williams y Locke son diferentes, y ello se refleja con toda claridad en el uso de términos. El primero quiere que se deje de perseguir, es decir, se trata de una disposición negativa, negarse a la persecución por causa de conciencia; el segundo, quiere no solo que no se persiga, sino también que se tenga una disposición positiva de tolerancia, y fundamentada precisamente en el piso cultural común compartido por quienes disienten, el cristianismo. Así, puede decirse que, al tiempo que Williams elabora un argumento en favor de la diferencia civilizada, Locke lo hace en favor de un acuerdo mínimo y, en tal sentido, ya no se trata solamente de proteger la libertad de conciencia término por lo demás no exento de ambigüedad a lo largo de su obra-, sino sobre todo de domesticarla (Svensson, 2011).

\section{Williams, entre Agustín y Locke. Conclusiones sumarias}

Williams se encuentra en una frontera. Por un lado tiene al cristianismo altomedieval de Agustín y, por otro, al liberalismo de Locke. Con Agustín, trae a los tiempos modernos la distinción entre dos órdenes distintos, orientados a distintos fines. Uno, la Iglesia; otro, la ciudad terrenal. Trae también con él la distinción entre dos tipos de paz: aquella de la ciudad celeste y la de la ciudad terrena. De aquí que también trae con él la diferencia entre dos órdenes normativos: el de la Iglesia y el de la ciudad. También trae consigo una definición del orden social terrenal como uno fundado sobre la familia. Y, contra él, disiente respecto a la posibilidad de perseguir a causa de la creencia y conciencia, posición que Agustín adoptó en particular frente a ciertas expresiones donatistas.

Williams rechaza la persecución por causa de conciencia no porque sea un liberal, sino porque considera que no está dentro del horizonte normativo de la Iglesia ni de la ciudad el hacerlo. Solo considera que debe haber una acción coercitiva del orden civil en materia de creencias cuando estas traigan inestabilidad a la ciudad mediante la provocación y la violencia. Pero, de todas formas, el orden civil puede hacer ello con todo tipo de violencia, no solo con la inspirada en razones religiosas. Desde luego, aquí también puede haber diferencias con ideas medievales distintas de las de Agustín que apostaban por una vinculación más estrecha entre Iglesia y Estado y que, en suma, buscaban que este último mantuviese en un lugar privilegiado a la fe católica. Situación análoga ocurre con las ideas protestantes como la de un primer calvinismo al estilo de Ginebra, en el que se concebía que el Estado debía promover una religión particular en desmedro de otras. Así las cosas, no es a pesar de la matriz agustiniana de pensamiento, sino gracias a ella, que Williams logra elaborar una propuesta particular en su tiempo a favor de la neutralidad del Estado y de la libertad de conciencia.

Curiosamente, mientras que las diferencias entre Williams y Agustín son menores pese a estar a más de 1000 años de distancia, con Locke, un casi contemporáneo cuya distancia cronológica no supera los 30 años, existen diferencias de mayor calado. En tal sentido, Williams mantiene una visión agustiniana de la Iglesia según la cual se trata de una comunidad orientada a fines espirituales y, si bien Locke también acepta que sus fines son distintos, atribuye su existencia fundamentalmente al acuerdo entre individuos que convienen un cierto modo de entender la religión. En suma, sitúa su existencia no en la voluntad divina, sino en la voluntad de los hombres. Una segunda diferencia sustantiva reside en que mientras que Williams concibe a la ciudad o Estado como una comunidad organizada sobre el fundamento de la familia, Locke cifra su fundamento en el contrato de los individuos. De este modo, la ciudad ya no es más un conjunto de comunidades conviviendo en armonía, como podría pensarse 
desde un punto de vista clásico, sino una pléyade de individuos que conforman asociaciones voluntarias.

Tales dos diferencias tienen consecuencias importantes en el modo en que ambos conciben la libertad de conciencia y creencia. En efecto, si bien en Williams y Locke observamos que el orden civil exige como mínimo la aceptación de la existencia de diferencias doctrinales de parte de los distintos grupos para una coexistencia pacífica, y que ambos entienden por principio que el Estado no debe entrometerse en materias propias de la vida religiosa, las implicaciones del pensamiento liberal de Locke lo distancian irremediablemente de Williams. Este último, al comprender la paz civil desde un punto de vista de las familias y comunidades que componen la ciudad, no se interesa en explorar argumentos para alcanzar la armonía entre grupos inexorablemente opuestos. Más bien, se limita a condenar el empleo de la violencia ante las diferencias irreconciliables de estos grupos. Locke, en cambio, cifra el principio no solo del Estado, sino también de la Iglesia, en la voluntad contractual de los individuos. Por eso, no se contenta con condenar la violencia y abogar por la neutralidad estatal, sino que apela a la tolerancia como una característica de la verdadera Iglesia. Pero aquí Iglesia no designa comunidad sino, ante todo, un conjunto de individuos.

Por lo tanto, en última instancia, Locke cifra la esperanza de la paz civil entre grupos religiosos no en la capacidad de las agrupaciones para resolver sus diferencias, sino en la disposición de los individuos a tolerarse mutuamente. De este modo, su visión liberal le permite desplazar el conflicto desde los grupos hacia los individuos y esto, a su vez, sobre el presupuesto de que eventualmente los individuos serían capaces de lograr por voluntad individual mancomunada lo que no se puede desde un enfoque de comunidades religiosas. El concepto de tolerancia lockeano solo puede sostenerse sobre estas presuposiciones respecto a la naturaleza de la Iglesia y del Estado, y en ambos casos se trata de concepciones opuestas a las de Williams. Mientras que en Williams hay un bien común que conforma al Estado, y de lo que se trata no es de remitir la religión al individuo, sino distinguir el bien de las comunidades religiosas del bien del Estado; en Locke, el individualismo y no el bien común es lo que conforma al Estado, dejando así la cuestión religiosa en manos del individuo.
En Locke, la civilidad se funda en la aceptación de un mínimo común, a saber: toda Iglesia verdadera es tolerante, por lo tanto, si una Iglesia reclama ser verdadera, aquello ha de expresarse en su tolerancia. De este modo, todas las iglesias que reclaman ser verdaderas - ¿y cual no? - lo expresarán en su tolerancia por los diferentes. Pero esto solo puede lograrse aceptando la presuposición de que las iglesias que reclaman ser verdaderas son organizaciones conformadas por individuos racionales de manera contractual. Esta presuposición es inadmisible para alguien como Williams, pues para él sí hay verdades teológicas superiores a otras; por lo tanto, para él la confesión de esas verdades no se cifra en la tolerancia, sino en la más recta comprensión de las enseñanzas del cristianismo. Asimismo, para él la Iglesia no es una asociación conformada por individuos, sino una entidad proveniente de la voluntad divina. Por ello, a diferencia de Locke, la civilidad o paz de la ciudad no puede cifrarse en una noción de esa naturaleza en la cual se alcanza un acuerdo colocando a la tolerancia como centro de la verdad, sino todo lo contrario: la paz de una ciudad en que cohabitan grupos religiosos opuestos se alcanza sobre la aceptación de que no es posible encontrar un mínimo común respecto a la verdad. En términos de convivencia cívica, podría decirse que para Locke de lo que se trata es de gobernar domesticando las conciencias, y que para Williams de lo que se trata es de gobernar pese a las conciencias.

Mientras que en Locke la tolerancia surge como fruto de la fe verdadera de los individuos cristianos, para Williams la tolerancia surge de la aceptación de la imposible reconciliación entre grupos. Si acaso hay algún mínimo común en Williams, ese mínimo es reconocer la distinción entre las dos ciudades, basada sobre el reconocimiento de sus fines distintos y que tendría por consecuencia que ninguno de los grupos pese a sus diferencias, quiera imponerse sobre el otro mediante la fuerza. Todo el tratado de Williams está repleto de citas bíblicas e históricas para fundamentar esta posición. Para quienes aun así no quieran aceptarla y persistan en imponerse por la violencia o buscar que el Estado persiga a los diferentes; contra ellos queda entonces la fuerza del Estado no por causa de conciencia o creencias, sino por causa de violencia. Y en esto, Agustín, Williams y Locke sí estuvieron de acuerdo. 


\section{Notas}

1 Los aspectos biográficos a continuación son tomados de la "Introducción" a El sangriento dogma, Blázquez (2004).

2 Las cursivas y mayúsculas se conservan siempre tal como están en la traducción al español del texto de Williams (2004) que usamos aquí.

3 Todas las traducciones presentadas en el artículo son propias.

4 El donatismo fue un movimiento cismático del siglo IV surgido en el norte de África, llamado con ese nombre en referencia a su líder, el obispo Donato, y se caracterizó por una fuerte estrictez que se expresaba en hacer "depender la eficacia de los sacramentos de la dignidad o indignidad personal de los ministros que los dispensaban, no solo en cuanto a la ortodoxia de la fe, sino también en cuanto a moralidad" (Álvarez, 2001, p. 236). Todo ello se dio en el marco de un problema más amplio, a saber, el hecho de que hubiese cristianos que, habiendo renunciado a su fe en períodos de persecución, buscaban retornar a la fe de la Iglesia.

\section{Referencias bibliográficas}

Agustín de Hipona. (2009). La ciudad de Dios. Biblioteca de Autores Cristianos.

Álvarez, J. (2001). Historia de la Iglesia. I. Edad Antigua. Madrid: Biblioteca de Autores Cristianos.

Álvarez, S. (1960). Hacia la determinación de la idea agustiniana de paz. Revista de Estudios Políticos, 112, 49-90.

Bejan, T. (2017). Mere Civility. Harvard University Press.

Bejczy, I. (1997). Tolerantia. A Medieval Concept. Journal of the History of Ideas, 58(3), 365-384. https://doi.org/10.1353/jhi.1997.0024.

Blázquez, D. (2004). Introducción. En R. Williams, El sangriento dogma de la persecución por causa de conciencia (XXI-XLV). Centro de Estudios Políticos y Constitucionales.

Gray, J. (2000). Pluralismo de valores y tolerancia liberal. Centro de Estudios Públicos, $80,77-93$.

Gutman, A. (2004). Identity in Democracy. Princeton University Press.

Kaufman, P. (1990). Redeeming Politics. Nueva Jersey: Princeton University Press.

Little, D. (2016). Constitutional Protection of the Freedom of Conscience in Colonial America: The Rhode Island and Pennsylvania Experiments. En T. S. Shah y A. D. Hertzke (Eds.), Christianity and Freedom (235-263). Cambridge University Press.

Locke, J. (2018 [1689]). Carta sobre la tolerancia. Tecnos.

Mansuy, D., y Svensson, M. (2013). Tolerance. En K. Pollman y W. Otten (Eds.), The Oxford Guide to the Historical Reception of Augustine (pp. 1815-1818). Oxford University Press.

Naciones Unidas. (1948). La Declaración Universal de Derechos Humanos. Nueva York: United Nations. Recuperado de https://www.un.org/es/universal-declarationhuman-rights/.

Nussbaum, M. (2012). The New Religious Intolerance. The Belknap Press.

Rist, J. (2016). Augustine and Religious Freedom. En T. S. Shah y A. D. Hertzke (Eds.), Christianity and Freedom (pp. 103-122). Cambridge University Press.

Rodríguez, R. (2010). Liberalismo y comunitarismo. Un debate inacabado. Revista de Humanidades, 16, 201-229.

Svensson, M. (2011). Conciencia moral y libertad de conciencia en Locke. Ideas y valores, 60(146), 141-164.

Williams, R. (2004 [1644]). El sangriento dogma de la persecución por causa de conciencia. Centro de Estudios Políticos y Constitucionales. 